\title{
HIV-Associated Cardiovascular Disease
}

\section{Role of Connexin 43}

\author{
Lisa Prevedel, ${ }^{* \dagger}$ Camilla Morocho, ${ }^{* \dagger}$ Michael V.L. Bennett, ${ }^{\dagger}$ and Eliseo A. Eugenin ${ }^{* \dagger}$
}

From the Public Health Research Institute (PHRI), * and the Department of Microbiology, Biochemistry and Molecular Genetics, ${ }^{\dagger}$ Rutgers New Jersey Medical School, Rutgers the State University of New Jersey, Newark, New Jersey; and the Department of Neuroscience, ${ }^{\ddagger}$ Albert Einstein College of Medicine, Bronx, New York

\author{
Accepted for publication \\ May 1, 2017. \\ Address correspondence to \\ Eliseo A. Eugenin, Ph.D. \\ Public Health Research Institute \\ (PHRI) and Department of \\ Microbiology, Biochemistry \\ and Molecular Genetics, \\ Rutgers New Jersey Medical \\ School, Rutgers The State \\ University of New Jersey, \\ 225 Warren Street, Newark, \\ NJ. E-mail: eliseo.eugenin@ \\ rutgers.edu.
}

\begin{abstract}
Chronic HIV infection due to effective antiretroviral treatment has resulted in a broad range of clinical complications, including accelerated heart disease. Individuals with HIV infection have a 1.5 to 2 times higher incidence of cardiovascular diseases than their uninfected counterparts; however, the underlying mechanisms are poorly understood. To explore the link between HIV infection and cardiovascular diseases, we used postmortem human heart tissues obtained from HIV-infected and control uninfected individuals to examine connexin 43 (Cx43) expression and distribution and HIV-associated inflammation. Here, we demonstrate that $\mathrm{C} \times 43$ is dysregulated in the hearts of HIV-infected individuals. In all HIV heart samples analyzed, there were areas where $\mathrm{C} \times 43$ was overexpressed and found along the lateral membrane of the cardiomyocyte and in the intercalated disks. Areas of HIV tissue with anomalous Cx43 expression and localization also showed calcium overload, sarcofilamental atrophy, and accumulation of collagen. All these changes were independent of viral replication, CD4 counts, inflammation, and type of antiretroviral treatment. Overall, we propose that HIV infection increases $\mathrm{Cx} 43$ expression in heart, resulting in tissue damage that likely contributes to the high rates of cardiovascular disease in HIV-infected individuals. (Am J Pathol 2017, 187: 1960-1970; http://dx.doi.org/10.1016/j.ajpath.2017.05.011)
\end{abstract}

HIV/AIDS represents a growing concern with an estimated 36 million cases worldwide and 1.2 million in the United States. The introduction of effective antiretroviral treatment (ART) has led to increased life span of HIV-infected $\left(\mathrm{HIV}^{+}\right)$individuals almost becoming a chronic disease. However, the prevalence of cardiovascular disease or cardiomyopathy in the HIV-infected population is 1.5 to 2 times higher than in the uninfected $\left(\mathrm{HIV}^{-}\right)$population ${ }^{1-4}$ and may be due to chronic inflammation, hypertension, endothelial dysfunction, insulin resistance, toxicity of antiretroviral drugs, and dyslipidemia. ${ }^{5-7}$ HIV cardiomyopathy is characterized by loss of cardiomyocytes and their replacement by fibrous tissue and infiltration of immune cells. $^{8-10}$ However, the pathogenesis of heart disease in $\mathrm{HIV}^{+}$individuals remains largely unknown. We propose that the dysregulation of connexin 43 (Cx43) channels play a key role in the pathogenesis of HIV heart disease.

Gap junctions (GJs) allow the exchange of ions, metabolites, second messengers, and small RNAs and serve as low resistance bridges between coupled cells that enable action potential propagation in excitable tissues and coordination of metabolism. ${ }^{11}$ In the healthy adult heart, $\mathrm{Cx} 43$ is abundantly expressed in the myocardium and is mainly located in GJs at the intercalated disks. Alterations in Cx43 expression and/or subcellular distribution in the heart have been associated with several diseases, including hypertension, infarction, ischemia, hypertrophic cardiomyopathy, atrial fibrillation, and arrhythmias. ${ }^{12-17}$ However, the effect of HIV on Cx43 expression and distribution in the heart has

\footnotetext{
Supported by the NIH grants MH096625 and NS105584 (E.A.E.) and Public Health Research Institute funding (E.A.E.). The National NeuroAIDS Tissue Consortium is made possible through funding from the National Institute of Mental Health and National Institute of Neurological Disorders and Stroke by the Manhattan HIV Brain Bank grant U24MH100931, Texas NeuroAIDS Research Center grant U24MH100930, National Neurological AIDS Bank grant U24MH100929, California NeuroAIDS Tissue Network grant U24MH100928, and Data Coordinating Center grant U24MH100925.

Disclosures: None declared.
} 
not been examined. Recently, we described that HIV-tat protein, the trans-activator of the virus, binds to the $\mathrm{Cx} 43$ promoter in human astrocytes and enhances $\mathrm{Cx} 43$ expression, thereby increasing gap junctional communication and likely the number of open hemichannels. ${ }^{18}$ It is unknown whether the same mechanism of $\mathrm{Cx} 43$ up-regulation occurs in cardiomyocytes. Here, we report that $\mathrm{Cx} 43$ is overexpressed and mis-localized in all postmortem heart tissue samples analyzed from HIV-infected individuals. These changes in Cx43 were independent of CD4 counts, HIV replication status, and ART. Furthermore, areas with dysregulated $\mathrm{Cx} 43$ expression and distribution also have signs of calcium overload, mitochondrial proliferation, muscle compromise, and fibrosis. Thus, we propose that overexpressed $\mathrm{Cx} 43$ is a main contributor to the increased heart disease observed in HIV-infected individuals.

\section{Materials and Methods}

\section{Study Participants}

Donors were recruited by National NeuroAIDS Tissue Consortium (NNTC) as part of a National Institute of Mental Health and National Institute of Neurological Disorders and Stroke program to collect, store, and distribute samples obtained from $\mathrm{HIV}^{+}$and $\mathrm{HIV}^{-}$individuals. Uninfected and HIV-infected individuals were uniformly distributed among age and comorbidities (Table 1 and data not shown). The only uneven characteristic of our population was sex, most of our uninfected and HIV-infected samples were obtained from men. In addition, the population analyzed had a broad spectrum of CD4 counts, plasma viral load, ART, and length of HIV infection. The uninfected population analyzed was cognitively normal. In contrast, $49 \%$ of the HIV-infected population was neurocognitive normal (28 cases), $18 \%$ cognitive impaired (10 cases), $28 \%$ was cognitive impaired to other or uncertain cause (16 cases), and 5\% was unable to reliably assign neurocognitive diagnostic ( 3 cases). These data indicated that even HIV-infected individuals had normal cognition, yet they may have significant alterations in heart disease as demonstrated below.

\section{Immunofluorescence and Confocal Microscopy}

Tissue sections were incubated in blocking solution for 2 hours at room temperature and then in diluted primary antibody (anti-pan Cx43: dilution 1:2000, Sigma C6219; Sigma-Aldrich, St. Louis, MO; or anti-N-cadherin: dilution 1:250, BD 61092; Becton Dickinson, Franklin Lakes, NJ) overnight at $4^{\circ} \mathrm{C}$. Tissues were washed several times with phosphate-buffered saline at room temperature and incubated with the appropriate secondary antibody for at least 2 hours at room temperature, followed by another wash in phosphate-buffered saline. Tissues were examined using an A1 Nikon confocal microscope (Nikon, Tokyo, Japan).
Antibody specificity was confirmed by replacing the primary antibody with a nonspecific myeloma protein of the same isotype or nonimmune serum as previously described. ${ }^{19,20}$ The expression level and distribution of the target protein were analyzed using the three-dimensional reconstructions and deconvolution, followed by the generation of regions of interest. With the use of the corresponding regions of interest the numbers of positive pixels for the whole deconvoluted three-dimensional construction were calculated. The expression measurement was determined by quantifying the intensity of positive pixels for Cx43 and lipofuscin. To compare control and HIV conditions, a similar number of cells ( 300 to 800 cells) and total area were analyzed. This analysis avoids usual problems of this kind of experiment, such as changes in cell number or excessive inflammation. Details of the procedure, including deparaffinization, antigen retrieval, blocking, immunohistochemical staining with primary and secondary antibodies, and specificity testing, were previously described. ${ }^{19,21}$

\section{RNA Isolation and Quantitative RT-PCR}

Total RNA was isolated from $10-\mathrm{mm}^{3}$ pieces of ventricular heart using RNeasy plus universal tissue mini kit from Qiagen (Hilden, Germany) according to the manufacturer's instructions and quantified using a Nanodrop (Thermo Scientific, Wilmington, DE). Synthesis of cDNA was performed using iScript cDNA synthesis kit according to the manufacturer's instructions (Bio-Rad, Hercules, CA). Relative mRNA expression of Cx43 and glyceraldehyde-3-phosphate dehydrogenase (GAPDH) was determined using Sybr green kits (Life Technologies, Carlsbad, CA). Results are represented as a relative expression of $\mathrm{Cx} 43$ normalized to that of GAPDH as a housekeeping gene. The $\Delta \mathrm{Ct}$ value was determined by subtracting the average $\mathrm{Ct}$ of the housekeeping gene from the average $\mathrm{C}_{\mathrm{t}}$ of the $\mathrm{Cx} 43$ gene (official name GJAl). Expression of Cx43 mRNA was compared between the uninfected and HIV-infected individuals and analyzed by paired two-tailed $t$-test.

\section{Western Blot Analysis}

Small ventricular heart pieces were homogenized in RIPA buffer (Cell Signaling, Beverly, MA) containing protease inhibitors (Cell Signaling, Danvers, MA), and $40 \mu \mathrm{g}$ of protein was electrophoresed on a $10 \%$ polyacrylamide gel (Bio-Rad) and transferred to nitrocellulose membranes. Membranes were probed with rabbit antibodies to connexin43 (Sigma-Aldrich) and GAPDH (Santa Cruz Technologies, Carlsbad, CA). Densitometric analysis was performed using ImageJ software version $1.51 \mathrm{j} 8(\mathrm{NIH}$, Bethesda, MD).

\section{Von Kossa Staining}

Human heart tissue frozen sections were fixed in cold ethanol for 15 to 20 minutes. After rinsing, the fixed tissues 
Table 1 Patient Information

\begin{tabular}{|c|c|c|c|c|c|c|c|}
\hline Patient No. & HIV status & Age, years & Sex & $\begin{array}{l}\text { ART current ARVs } \\
\text { ( } 2 \text { years of death) }\end{array}$ & $\begin{array}{l}\text { CD4 counts, } \\
\text { cells } / \mathrm{mm}\end{array}$ & $\begin{array}{l}\text { Viral load, } \\
\text { copies/mL }\end{array}$ & Time with HIV, years \\
\hline 1 & + & 45 & M & $\begin{array}{l}\text { 3TC, ABC, APV, CBV, D4T, DDC, } \\
\text { DDI, DLV, EFV, HU, IDV, NFV, } \\
\text { NVP, RTV, SQV, ZDV }\end{array}$ & 25 & 124,380 & 13 \\
\hline 2 & + & 58 & M & 3TC, ABC, APV, DDI, IDV, NVP, ZDV & 87 & 3806 & 9 \\
\hline 3 & + & 24 & M & NR & 141 & NR & $<1$ \\
\hline 6 & + & 55 & M & $3 T C$ & 3 & 240,337 & 7 \\
\hline 7 & + & 58 & M & 3TC, ABC, EFV, KTA, RTV & 72 & 279 & $<1$ \\
\hline 8 & + & 43 & M & ABC, KTA, NVP, RTV, TFV & 12 & 90,258 & 16 \\
\hline 9 & + & 47 & M & 3TC, KTA, NFV, NVP, RTV, TFV, ZDV & 199 & NR & 17 \\
\hline 10 & + & 52 & M & NR & NR & NR & 16 \\
\hline 15 & + & 52 & M & NR & 630 & 40 & 23 \\
\hline 16 & + & 49 & M & 3TC, ABC, KTA, RTV, TFV, TZV, ZDV & 273 & 400 & 10 \\
\hline 17 & + & 44 & M & NR & 78 & 3484 & 4 \\
\hline 18 & + & 64 & M & DRV, EPZ, RTV & 299 & 40 & 18 \\
\hline 19 & + & 39 & M & D4T, DDI, NFV & NR & 400 & 7 \\
\hline 20 & + & 35 & M & $A B C, A P V, D 4 T$ & 40 & 250,000 & 13 \\
\hline 21 & - & 69 & $M$ & NA & NA & NA & NA \\
\hline 22 & - & 38 & M & NA & NA & NA & NA \\
\hline 23 & - & 51 & $\mathrm{~F}$ & NA & NA & NA & NA \\
\hline 24 & - & 54 & M & NA & NA & NA & NA \\
\hline 25 & - & 66 & M & NA & NA & NA & NA \\
\hline 34 & + & 59 & M & 3TC, CBV, D4T, NVP, TRU & 158 & 40 & 13 \\
\hline 35 & + & 60 & M & $\mathrm{EPZ}, \mathrm{KTA}$ & 497 & 48 & 6 \\
\hline 36 & + & 54 & M & $\begin{array}{l}\text { 3TC, ABC, ATR, ATV, CBV, DRV, EPZ, } \\
\text { KTA, NFV, RTV, TRU }\end{array}$ & 384 & 40 & 12 \\
\hline 37 & + & 71 & M & 3TC, ATV, KTA, RTV, TRU, ZDV & 403 & 40 & 16 \\
\hline 38 & + & 61 & M & NR & 315 & NR & 20 \\
\hline 39 & + & 39 & M & DRV, KTA，RTV，TRU & 112 & 40 & 15 \\
\hline 40 & + & 31 & M & NR & NR & 16,032 & 2 \\
\hline 41 & + & 34 & M & NR & NR & 54,148 & 6 \\
\hline 42 & + & 64 & M & 3TC, D4T & 96 & 2064 & 12 \\
\hline 43 & + & 50 & M & TZV & 256 & 400 & 15 \\
\hline 44 & + & 40 & M & NR & NR & NR & 5 \\
\hline 45 & + & 39 & M & 3TC, ABC, D4T, EFV, IDV, KTA, NVP & 13 & 75,000 & 14 \\
\hline 46 & + & 59 & M & 3TC, DDC, DLV, EFV, TFV, ZDV & 32 & 400 & 12 \\
\hline 47 & + & 37 & M & NR & NR & 30,769 & 9 \\
\hline 48 & + & 43 & M & NR & NR & NR & NR \\
\hline 49 & + & 29 & $\mathrm{~F}$ & NR & NR & NR & 10 \\
\hline 50 & + & 37 & M & NR & 24 & NR & 5 \\
\hline 51 & + & 35 & M & ATV, FTC, RTV, TFV & NR & NR & 11 \\
\hline 52 & + & 52 & M & 3TC, D4T, NVP & 41 & 400 & 7 \\
\hline 53 & + & 34 & M & ATV, RTV, TRU & 24 & 322 & 6 \\
\hline
\end{tabular}


Table 1 (continued)

\begin{tabular}{|c|c|c|c|c|c|c|c|}
\hline Patient No. & HIV status & Age, years & Sex & $\begin{array}{l}\text { ART current ARVs } \\
\text { ( } 2 \text { years of death) }\end{array}$ & $\begin{array}{l}\text { CD4 counts, } \\
\text { cells } / \mathrm{mm}\end{array}$ & $\begin{array}{l}\text { Viral load, } \\
\text { copies/mL }\end{array}$ & Time with HIV, years \\
\hline 54 & + & 58 & M & NR & 5 & 505,903 & 23 \\
\hline 56 & + & 57 & M & KTA, TRU & 518 & 50 & 17 \\
\hline 57 & - & 83 & M & NA & NA & NA & NA \\
\hline 58 & + & 25 & M & NR & NR & NR & NR \\
\hline 61 & - & 53 & $\mathrm{~F}$ & NA & NA & NA & NA \\
\hline 62 & + & 70 & M & $\mathrm{EPZ}, \mathrm{TMC}$ & NR & $<50$ & NR \\
\hline 63 & - & 58 & M & NA & NA & NA & NA \\
\hline 64 & - & 43 & M & NA & NA & NA & NA \\
\hline 65 & + & 59 & M & NR & 32 & 83,804 & $<1$ \\
\hline
\end{tabular}

F, female; M, male; 3TC, lamivudine (Epivir); ABC, abacavir (Ziagen); APV, amprenavir (Agenerase); ART, antiretroviral treatment; ARV, antiretroviral; ATR, efavirenz $600 \mathrm{mg}$ + emtricitabine $200 \mathrm{mg}$ + tenofivir DF $300 \mathrm{mg}$ (Atripla); ATV, atazanavir (Reyataz); CBV, zidovudine + lamivudine (Combivir); D4T, stavudine (Zerit); DDC, zalcitabine (Hivid); DDI, didanosine (Videx); DLV, delaviridine (Rescriptor); DRV, TMC-114, darunavir (Prezista); EFV, efavirenz (Sustiva); EPZ, ziagen + epivir (Epzicom); FTC, emtricitabine (Coviracil; Emtriva); FTV, SQV2, saquinavir-sgc (Fortovase); HU, hydroxyurea; IDV, indinavir (Crixivan); KTA, LPV/RTV, lopinavir/ritonavir (Kaletra); NA, not applicable; ND, not determined; NFV, nelfinavir (Viracept); NR, not recorded; NVP, nevirapine (Viramune); RTV, ritonavir (Norvir); SQV, saquinavir (Invirase); TFV, tenofivir DF (Viread); TMC, TMC-125, etravirine (Intelence); TRU, emtricitabine + tenofovir (Truvada); TZV, AZT + 3 TC + abacavir; zidovudine + lamivudine + abacavir (Trizivir); ZDV, zidovudine (alias AZT; Retrovir).

were incubated with $5 \%$ silver nitrate solution (ab150687; Abcam, Cambridge, UK) and cross-linked under UV light for 30 minutes and then rinsed twice with distilled water. The tissue sections were incubated with $(5 \%)$ sodium thiosulfate solution for 5 minutes, rinsed twice with distilled water, incubated with Nuclear Fast Red solution for 5 minutes, and rinsed three times with distilled water to remove excess stain. Serial sections were used to identify areas with compromised $\mathrm{Cx} 43$ expression.

\section{Electron Microscopy}

Fresh postmortem samples were fixed with $2.5 \%$ glutaraldehyde, $2 \%$ paraformaldehyde in $0.1 \mathrm{~mol} / \mathrm{L}$ sodium cacodylate buffer, postfixed in $1 \%$ osmium tetroxide, followed by $2 \%$ uranyl acetate, dehydrated through a graded series of ethanol, and embedded in LX112 resin (LADD Research Industries, Burlington, VT). Ultrathin sections were cut on a Reichert Ultracut UCT, stained with uranyl acetate, followed by lead citrate, and viewed on a JEOL 1200EX transmission electron microscope at $80 \mathrm{kv}$.

\section{Statistical Analysis}

Statistical analyses were performed using Origin Lab software version 7.2 (OriginLab Corporation, Northampton, MA). Analysis of variance was used to compare the different groups.

\section{Results}

\section{Description of Our Cohort of Uninfected and HIV-Infected Individuals}

Our studies were focused on the regulation of cardiac $\mathrm{Cx} 43$ in HIV-infected individuals using postmortem human ventricular cardiac tissue obtained from 69 individuals (12 uninfected and 57 HIV-infected) as described in Table 1.

Our uninfected population was eight men and four women with a mean age of $57.8 \pm 13.7$ years. Our HIVinfected population was 55 men $(96.5 \%)$ and two women (3.5\%) with a mean age of $47.7 \pm 11.5$ years and mean duration of HIV infection of $11.5 \pm 6.7$ years, $6.89 \pm 1.57$ $\times 10^{4}$ HIV RNA copies/mL, and $157.3 \pm 164.61 \mathrm{CD} 4$ cells/ $\mathrm{mm}^{3}$ (Table 1). At the time of death, most of the $\mathrm{HIV}^{+}$ individuals were on ART that included protease inhibitors (Table 1), which have been reported to have intrinsic endothelial toxicity. ${ }^{22,23}$ Most of the individuals whose cardiac tissue was analyzed had been followed by the National NeuroAIDS Tissue Consortium (Table 1).

\section{HIV-Infected Individuals Have Increased Expression and Mislocalization of $\mathrm{C} \times 43$}

Ventricular tissue sections were stained for $\mathrm{Cx} 43$ to analyze expression and distribution by confocal microscopy. Normally, Cx43 mainly localizes at contacts between myocytes at the intercalated disks. ${ }^{16,24-27} \mathrm{Cx} 43$ containing GJs form a 


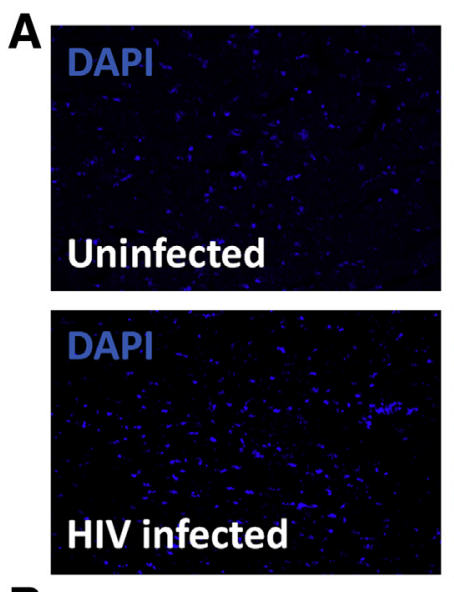

B

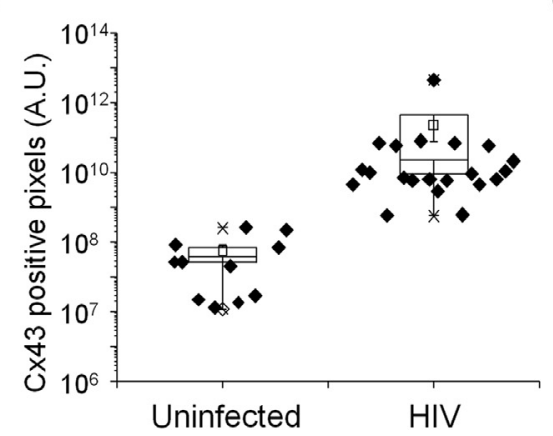

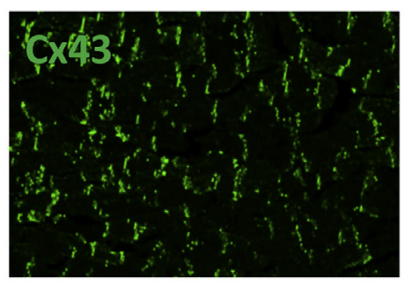
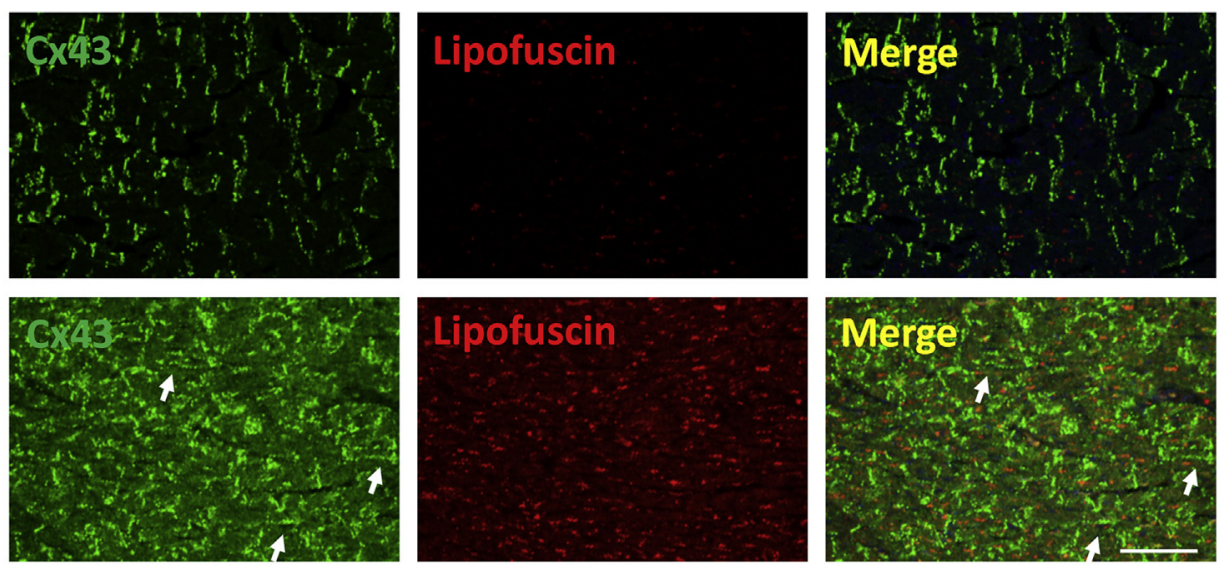

C

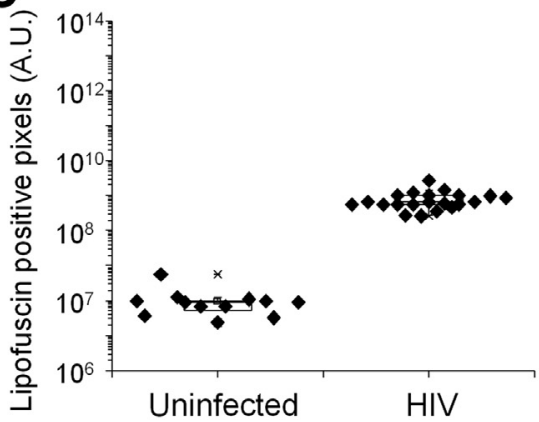

D

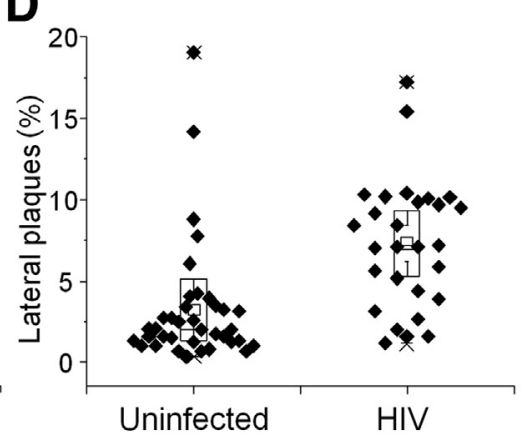

Figure 1 Expression of connexin $43(\mathrm{C} \times 43)$ in human hearts is up-regulated in HIV-infected individuals compared with heart tissues obtained from uninfected individuals. Postmortem ventricular heart tissue was obtained at the time of autopsy from uninfected and $\mathrm{HIV}^{-i n f e c t e d}$ individuals (HIV ${ }^{+}$) as described in Table 1. Because of the limited numbers of uninfected hearts, two to three distinct areas were quantified. A: Immunohistochemistry was performed using paraffin-embedded and fresh tissues and analyzed by confocal microscopy. Representative tissue staining for nuclei (DAPI), Cx43 (fluorescein isothiocyanate), and lipofuscin (red) in uninfected and HIV-infected individuals. Arrows indicate the Cx43 lateralization in the tissues. Cx43 was up-regulated at the intercalated disks and in the lateral membrane of the cardiomyocytes in all individuals analyzed. B: Quantification of Cx43-positive pixels in human ventricular tissue sections from uninfected and HIV-infected individuals. C: Quantification of the total number of lipofuscin-positive pixels was obtained in uninfected and HIV-infected individuals. D: Quantification of Cx43 containing lateral plaques in cardiac ventricular tissue sections obtained from uninfected and HIV-infected individuals. Data are expressed as means \pm SD. $n=69$ samples (A); $n=3$ tissue sections per individual (B and $\mathbf{D}$ ); $n=2$ tissue sections per individual (C). Scale bar $=200 \mu \mathrm{m}$. A.U., arbitrary unit.

low resistance bridge between cardiomyocytes that mediate action potential propagation and metabolic communication along the muscle fiber. Changes in expression and localization of GJs underlie several forms of heart disease. . $^{8,14,16,26,28-35}$ Our data confirmed that $\mathrm{Cx} 43$ in the heart from uninfected individuals was mainly localized at the intercalated disks as expected $(n=12)$ (Figure 1A). However, in all HIV-infected individuals analyzed, irrespective of HIV replication status, CD4 counts, and antiretroviral used, Cx43 staining was increased compared with uninfected individuals $(n=57 ; P=0.001$; HIV compared with uninfected samples) (Figure 1, A and B). Furthermore, the increased $\mathrm{Cx}_{43}$ in hearts of HIV-infected individuals was distributed predominantly along the lateral margins of the muscle fibers instead of at the intercalated disks $(P=0.05)$ (Figure 1, A and D). Lateralization of $\mathrm{Cx} 43$ is associated with several heart diseases such as ischemia, reperfusion injury, and arrhythmias. ${ }^{8,12,14,16,26,28-35}$ Interestingly, increased expression of $\mathrm{Cx} 43$, its lateralization, and lipofuscin accumulation was present in all HIV-infected individuals analyzed $(P=0.0003)$ (Figure 1, A and C), suggesting chronic heart damage. Lipofuscin accumulation is also associated with accelerated aging (Figure 1, A and C). Thus, we propose that increased $\mathrm{Cx} 43$ expression and lateralization of the protein in HIV-infected individual results in damage to the heart.

To confirm that HIV infection induced the lateralization of $\mathrm{Cx} 43$ in cardiomyocytes, we stained for $\mathrm{Cx} 43$ and $\mathrm{N}$-cadherin to better define the three-dimensional structure of the intercalated disk as previously reported. ${ }^{36}$ In uninfected conditions $68.8 \% \pm 8.5 \%$ of $\mathrm{Cx} 43$ colocalized with $\mathrm{N}$-cadherin at the intercalated disks (Figure 2). In the HIV-infected condition, only $32.65 \% \pm 12.02 \%$ of $\mathrm{Cx} 43$ colocalized with $\mathrm{N}$-cadherin, supporting the hypothesis that $\mathrm{Cx} 43$ was mis-localized into lateral membranes of the cardiomyocytes $(P=0.0007$ versus uninfected tissues) (Figure 2).

To further demonstrate that HIV infection increased the expression of $\mathrm{Cx} 43$ in heart tissues, we performed quantitative RT-PCR and Western blot analysis of cardiac tissue obtained from HIV patients as described in Table 1. Both Cx43 mRNA ( $n=57 ; P=0.03$ ) (Figure $3, \mathrm{~A}$ and $\mathrm{B}$ ) and protein $(n=12 ; P=0.05)$ (Figure $3, \mathrm{C}$ and $\mathrm{D}$ ) were increased compared with heart tissue obtained from 

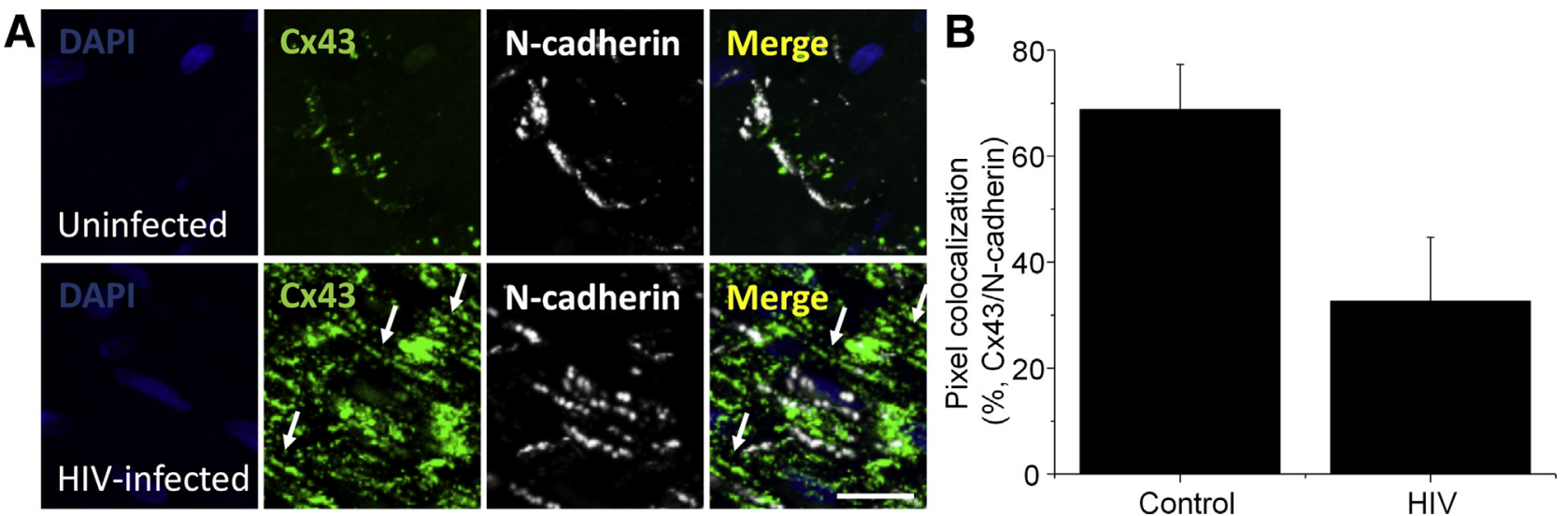

Figure 2 Lateralized connexin $43(\mathrm{C} \times 43)$ does not colocalize with $\mathrm{N}$-cadherin in heart tissues obtained from HIV-infected individuals. Postmortem ventricular heart tissue was used. Immunohistochemistry was performed using paraffin-embedded and fresh tissues and analyzed by confocal microscopy and three-dimensional reconstruction to examine colocalization of $\mathrm{C} \times 43$ and N-cadherin. A: Representative tissue staining for nuclei (DAPI), Cx43 (fluorescein isothiocyanate), and N-cadherin (cyanine 5) in uninfected and HIV-infected tissues. Arrows indicate lateralized Cx43 that also lacks staining for N-cadherin. In heart tissues obtained from uninfected individuals, most $\mathrm{C} \times 43$ localizes at the intercalated disk. In contrast, in heart tissues obtained from HIV-infected individuals, most $\mathrm{C} \times 43$ does not colocalize with $\mathrm{N}$-cadherin and mainly localizes at the lateral membrane of the cardiomyocyte. B: Quantification of Cx43positive pixels that colocalize with $\mathrm{N}$-cadherin-positive pixels in $\mathrm{HIV}^{-}$(control) and $\mathrm{HIV}^{+}$conditions. Data are expressed as means $\pm \mathrm{SD}$. Scale bar $=38 \mu \mathrm{m}$.

uninfected individuals. Our data confirmed the confocal data that $\mathrm{Cx} 43$ mRNA and protein increased in response to HIV infection in all cases analyzed. Further analysis of the HIV population described in Table 1 did not find any correlation between increased Cx43 (mRNA and protein) with type of antiretroviral treatment, CD4 counts, or viral load. The only feature that correlated with increased expression and localization of $\mathrm{Cx} 43$ was HIV infection.

\section{Calcium Is Dysregulated in Ventricular Areas with Compromised Cx43 Expression and Localization}

To examine whether changes in $\mathrm{Cx} 43$ localization and expression observed in heart tissue from HIV-infected individuals altered cardiomyocyte function, calcium metabolism was examined using Von Kossa staining. ${ }^{37-39}$ To perform these studies, serial tissue sections containing areas with normal and compromised $\mathrm{Cx} 43$ expression and localization were selected. Calcium normally diffuses through GJs ${ }^{31,40-42}$ and is sequestered into the mitochondria and endoplasmic reticulum or is extruded from the cell. ${ }^{43-46}$ In sections from uninfected individuals, Von Kossa staining was minimal, suggesting a normal calcium metabolism and diffusion (Figure 4A). In contrast, in tissue sections from $\mathrm{HIV}^{+}$individuals different degrees of pathologic calcium accumulation were observed (Figure 4A). Calcium overload was particularly evident in areas with overexpressed and lateralized $\mathrm{Cx} 43$ and pronounced lipofuscin staining (Figure 4A). Quantification of the calcium staining indicated that HIV-infected tissues had an increased calcium staining

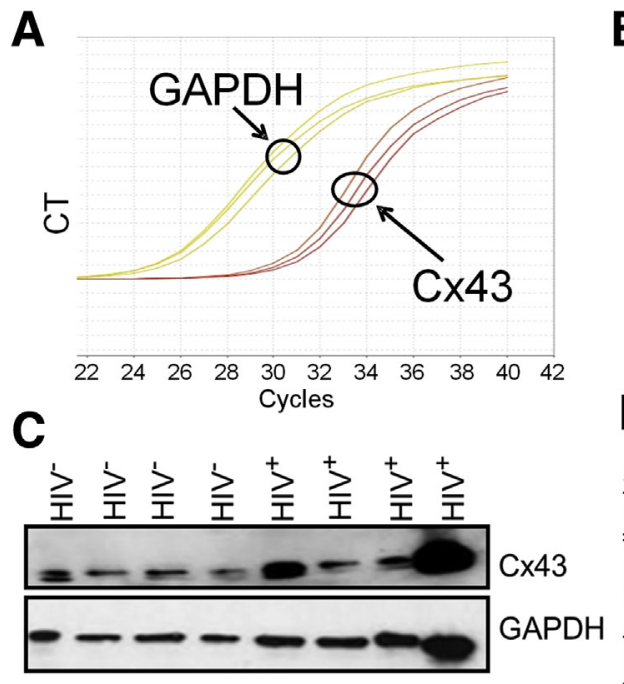

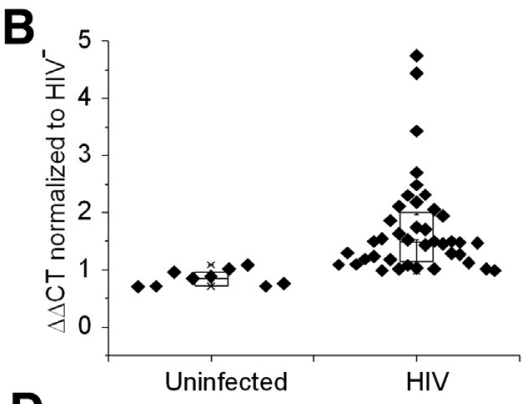

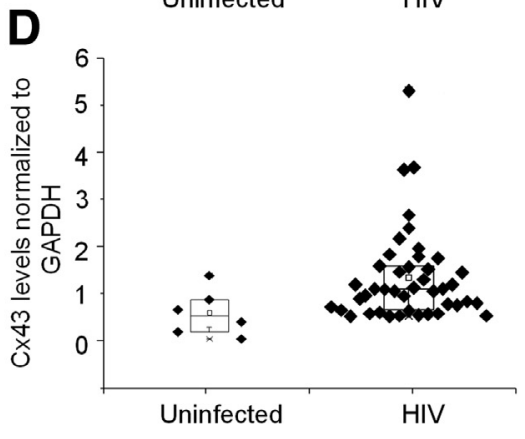

Figure 3 HIV infection increases expression of connexin 43 ( $(\times 43)$ mRNA and protein in human ventricular heart tissue. A: Representative quantitative RT-PCR (RT-qPCR) amplifications for glyceraldehyde-3-phosphate dehydrogenase (GAPDH) and Cx43. B: Quantification of the RT-qPCR experiments for tissues from uninfected and HIVinfected hearts. HIV infection (independent of antiretroviral treatment, CD4 counts, replication, and associated inflammation) increases Cx43 expression (mRNA and protein). Each point represents one individual. C: Representative Western blot analysis of $\mathrm{C} \times 43$ and GAPDH protein expression in $\mathrm{HIV}^{-}$and $\mathrm{HIV}^{+}$hearts. GAPDH was used as a loading control; mouse astrocytes were used as a positive control for $\mathrm{C} \times 43$ and its phosphorylation (data not shown). D: Quantification of the Western blots for heart tissues obtained from uninfected and HIV-infected individuals. Each point represents one individual. Data are expressed as means \pm SD. CT, cycle threshold. 

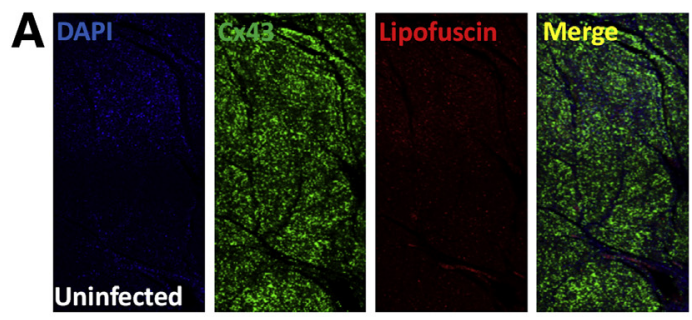

B

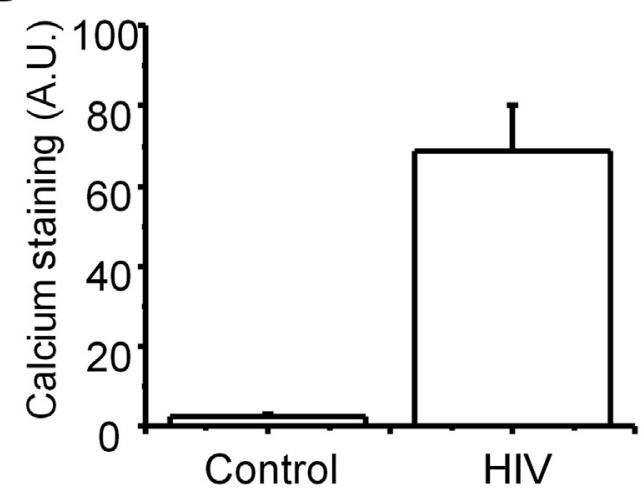

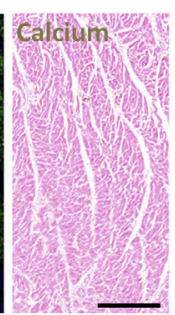
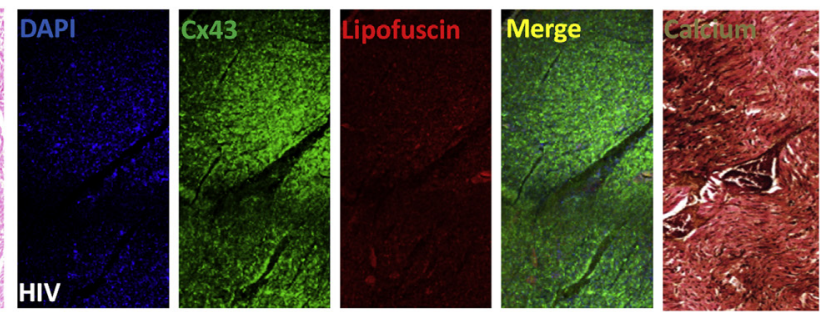

Figure 4 Areas with higher connexin 43 (Cx43) expression and mis-localization show calcium overload. Von Kossa staining to detect calcium deposits in heart sections from uninfected and HIV-infected individuals was performed. All these sections correspond to serial sections in which $C \times 43$ was up-regulated or mislocalized. Sections stained for DAPI, Cx43, and lipofuscin (autofluorescence), and the merge, correspond to the same tissue section. The adjacent tissue section was stained for Von Kossa (labeled calcium). A: Staining for tissue sections obtained from uninfected individuals (uninfected) showing normal $\mathrm{C} \times 43$ distribution and low accumulation of lipofuscin with minimal calcium deposits. Staining for tissue sections obtained from HIVinfected individuals $\left(\mathrm{HIV}^{+}\right)$showing increased expression of $\mathrm{C} \times 43$ in several areas of the tissue and increased accumulation of lipofuscin also shows increased accumulation of calcium deposits in vast areas of the tissue (different degrees of brown-back staining). B: Quantification of calcium staining (dark staining) indicates an increase of $60 \%$ in Von Kossa staining. Data are expressed as means \pm SD. $n=29$ different individuals ( $A$ and B). Scale bar $=200 \mu \mathrm{m}$. A.U., arbitrary unit. compared with control uninfected tissues $(n=16$; $P=0.005$ versus uninfected samples) (Figure 4B).

\section{Ventricular Regions with Altered Cx43 Expression and Localization Show Muscle Compromise and Mitochondrial Proliferation Compared with Areas without Cx43 Dysregulation}

Transmission electron microscopy was used to further evaluate the damage in the heart tissue. Two representative examples each of heart tissues obtained from an uninfected and an HIV-infected individual are shown in Figure 5, A and $\mathrm{B}$. In all $\mathrm{HIV}^{+}$tissues analyzed, there was an increase in the number of mitochondria $(P=0.00003)$ (Figure 5, $\mathrm{C}-\mathrm{E}$ ), especially in areas with compromised $\mathrm{Cx} 43$ expression and localization. In addition, significant decrease in myofibril width in areas with compromised mitochondria (Figure 5, C, D, and F) was detected. Quantification of the myofibril diameter clearly indicated that HIV-infected individuals have two different populations of fibers: myofibrils of normal diameter and myofibrils of about half that diameter compared with uninfected tissues $(P=0.01)$ (Figure 5F). No significant differences were observed if the two populations of myofibers were quantified compared with the diameter of uninfected myofibers. These compromised myofibrils were associated with the proliferation and altered distribution of mitochondria $(P<0.001$ versus uninfected conditions, $n=39$ ).

To further examine the damage in heart tissue obtained from HIV-infected individuals, trichrome stain for detection of collagen fibers and fibrin and periodic acid-Schiff for detection of polysaccharides was performed. Heart tissues obtained from uninfected cells have minimal trichrome staining, especially in blood vessels (Figure 6A). In contrast, $\mathrm{HIV}^{+}$heart tissue showed increased muscle disorganization as described above and increased accumulation of collagen or fibrin between the muscle fibers (Figure 6A). Quantification of the trichrome staining indicated a significant increase in accumulation of collagen or fibrin between cardiomyocytes in areas with compromised $\mathrm{Cx} 43$ expression and distribution $(P=0.001$ versus uninfected samples) (Figure 6B). No significant changes in periodic acid-Schiff staining were detected between uninfected and HIVinfected tissue sections (data not shown). In summary, significant damage was observed in areas with compromised Cx43 expression and localization.

\section{Discussion}

Our data demonstrate that HIV increases $\mathrm{Cx} 43$ expression at the intercalated disk and at the lateral membrane of the cardiomyocytes. We found that ventricular areas with $\mathrm{Cx} 43$ overexpression and mis-localization also have high calcium levels, increased fibrous tissue, and the proliferation of mitochondria. Thus, we propose that HIV-mediated upregulation of $\mathrm{Cx} 43$ contributes to the onset and progression of heart disease in $\mathrm{HIV}^{+}$individuals.

Despite the clinical importance of HIV heart disease the cause and contributing factors are poorly understood. Several laboratories using different models have demonstrated that HIV infection in combination with systemic inflammation and ART cytotoxicity results in cardiac pathologic processes. ${ }^{47-49}$ Furthermore, in the past couple of years, there is increasing clinical and experimental 

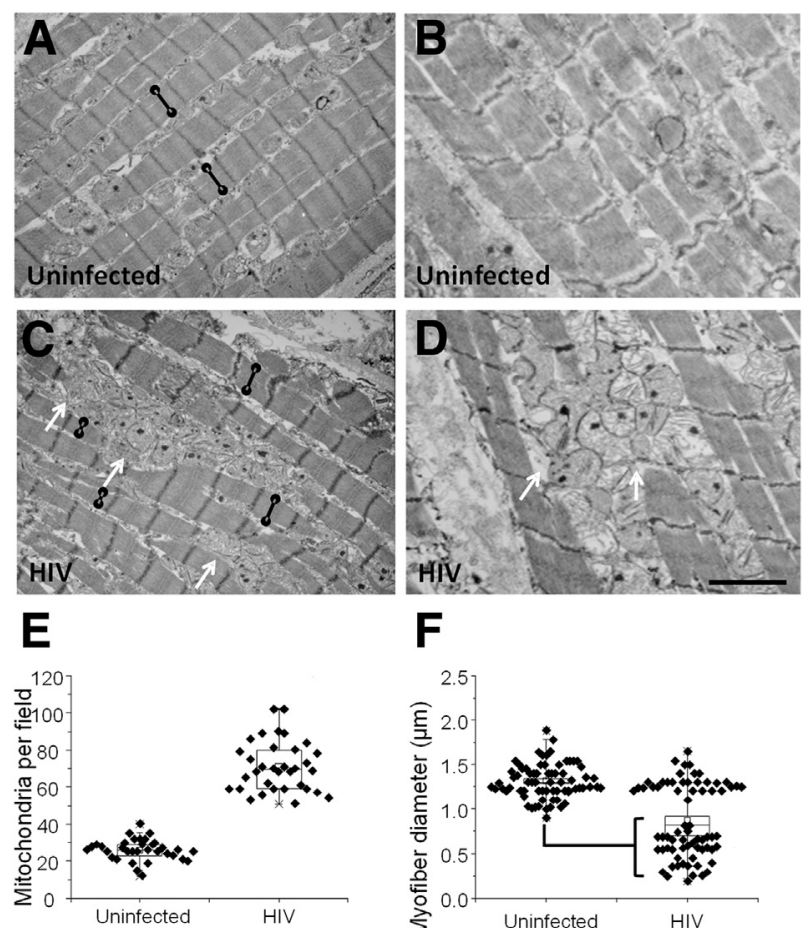

$\mathbf{F}$

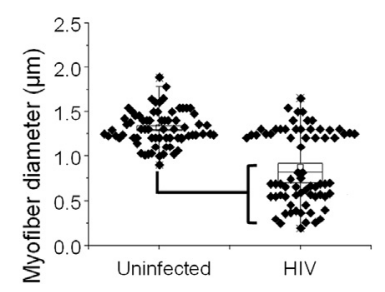

Figure 5 Electron microscopic analysis of hearts obtained from HIVinfected individuals shows that areas with compromised connexin 43 ( $C \times 43)$ localization and calcium metabolism have extensive mitochondrial proliferation and decreased myofibril width. Areas with normal and increased $\mathrm{C} \times 43$ expression were identified and subjected to electron microscopy analysis. A and B: Representative sections from an $\mathrm{HIV}^{-}$heart. Black lines with circles indicate myofibril width. C and D: Representative sections from an $\mathrm{HIV}^{+}$heart showing mitochondrial proliferation (arrows) and a decrease in myofibril width (black lines with circles). E: Quantification of mitochondrial numbers in heart tissue showing a significant increase in $\mathrm{HIV}^{+}$tissues. F: Quantification of myofibril width in heart tissues obtained from uninfected and HIV-infected individuals. There are no statistically significant differences between uninfected and HIV-infected individuals in myofibril width. However, analysis of tissues obtained from HIV-infected individuals indicates the presence of two distinct populations of myofibrils, one with normal width and a compromised one that is significantly different that that uninfected individual. Data are expressed as means \pm SD. $n=5$ grids per patient from five different individuals were analyzed $(\mathbf{F}) . P=0.01$, HIV small myofibers compared with uninfected conditions (F). Scale bar $=1.9 \mu \mathrm{m}$.

evidence that HIV infects cardiomyocytes in vitro and in vivo. ${ }^{50-52}$ Furthermore, it was reported that gp120 interaction with CXCR4 on the surface of cardiomyocytes triggers caspase-dependent mitochondrial activation and apoptosis. ${ }^{53}$ In addition to the potential direct effect of HIV in cardiomyocytes, several indirect mechanisms are also responsible for HIV heart damage, including an increase in proinflammatory cytokines, nitric oxide, and inducible nitric oxide synthase, which are released mainly by macrophages. ${ }^{54-56}$ In conclusion, several laboratories agree that the damage is multifactorial. Here, we propose that dysregulation of $\mathrm{Cx} 43$ also plays a role in HIV-associated cardiotoxicity.

$\mathrm{Cx} 43$ is an essential protein in heart development and function. ${ }^{12}$ In the normal heart, $\mathrm{Cx} 43$ is localized to intercalated disks, and little is found in the lateral membranes. Increased lateralization is often associated with reduced conduction velocity and increased in fibrosis. $^{12,14,16,25,30,31,57}$ Normally, under inflammatory and infectious conditions $\mathrm{Cx} 43$ expression and GJ communication is reduced or shut down. ${ }^{11,58}$ However, our data on astrocytes in the context of HIV infection indicate that the HIV protein, tat, the transactivator of the virus, binds to the $\mathrm{Cx} 43$ promoter, increasing $\mathrm{Cx} 43$ expression and gap junctional coupling to enable the spread of toxic intracellular second messengers among coupled cells, resulting in bystander apoptosis and inflammation. ${ }^{18,58}$
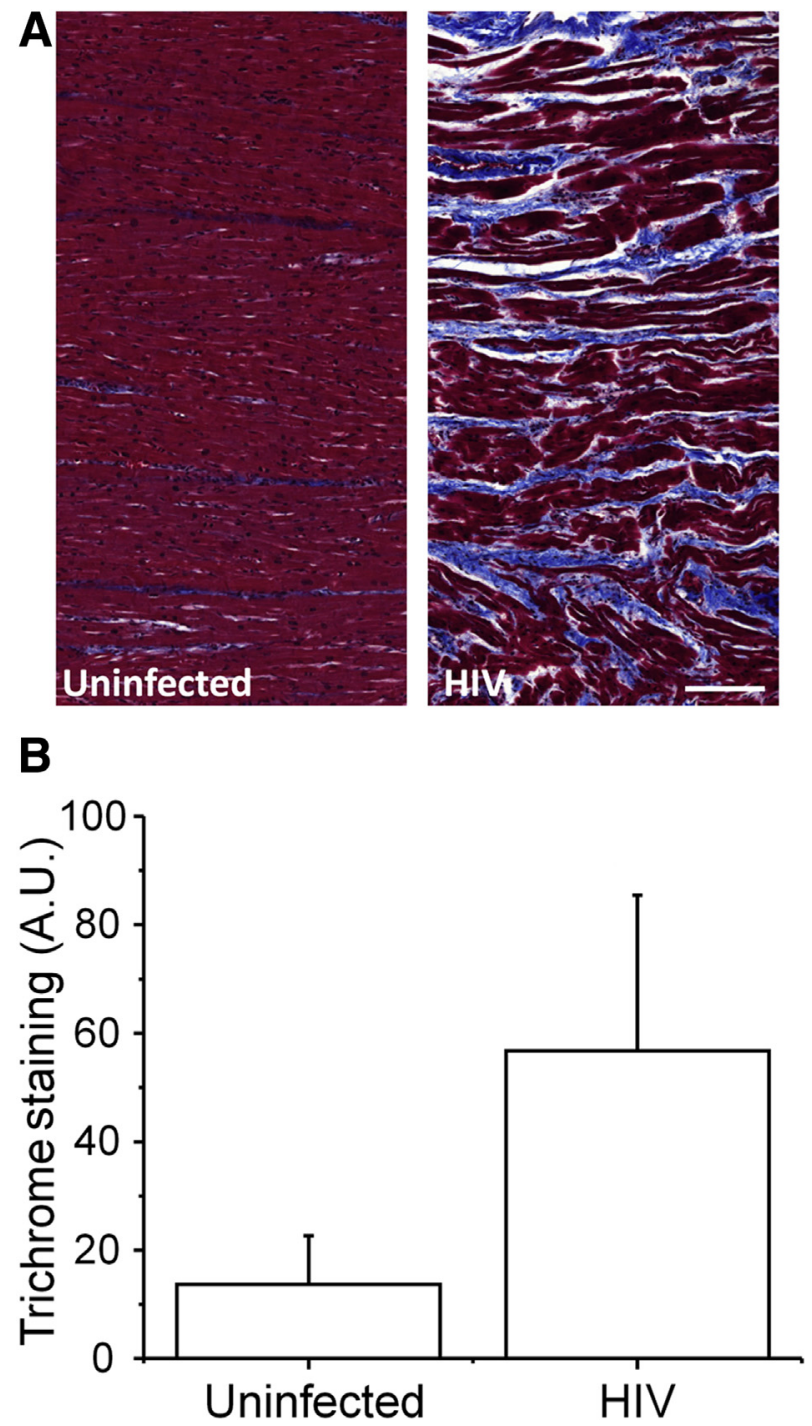

Figure 6 HIV infection increases the accumulation of collagen/fibrin in areas with increased expression and mis-localized connexin 43 (Cx43). Trichrome staining (blue) was performed to detect accumulation of collagen and fibrin in serial sections with areas already identified to have increased and mis-localized Cx43 expression. A: Trichrome staining of tissue sections obtained from uninfected and HIV-infected individuals. B: Quantification of trichrome staining from individuals indicates that HIV infection increases tissue scaring. $n=10$ uninfected individuals (A and B); $n=19$ HIV-infected individuals (A and $\mathbf{B}$ ). Scale bar $=200$ $\mu \mathrm{m}$. A.U., arbitrary unit. Data are expressed as means \pm SD. 
HIV-tat, like other viral proteins, is secreted into the extracellular space even in the presence of effective $\mathrm{ART}^{59,60}$ and may enter and affect cells that do not express HIV-tat. Our data indicate that in all of the heart tissues analyzed from HIV-infected individuals Cx43 was increased in abundance and was anomalously distributed along the lateral membranes. The lateral localization of $\mathrm{Cx} 43$ protein and the separation between the different muscle fibers suggest that $\mathrm{Cx} 43$ hemichannels may be an additional source of cellular compromise and inflammation as described in other systems. ${ }^{58,61,62}$ Opening of $\mathrm{Cx} 43$ hemichannels would increase $\mathrm{Ca}^{2+}$ influx into cardiomyocytes and allow $\mathrm{Na}^{+}$influx, and $\mathrm{K}^{+}$efflux and loss of ATP and other metabolites into the extracellular space. In agreement with the suggestion of increased hemichannel opening, our data indicate that all HIV-infected individuals have increased circulation of intracellular molecules transported by the opening of hemichannels. Furthermore, HIV infection of astrocytes and cell lines susceptible to HIV infection also results in the opening of $\mathrm{Cx} 43$ containing hemichannels. ${ }^{18,58,63}$ Thus, further studies are required to examine the role of $\mathrm{Cx} 43$ hemichannels in HIV-associated heart disease.

The increased accumulation of lipofuscin indicates accelerated aging processes in the HIV-infected population as described in other HIV-related pathologic conditions. ${ }^{64}$ Lipofuscin is a brownish pigment generated by the breakdown and absorption of damaged blood cells or lipids and is associated with aging. Thus, higher amounts of lipofuscin are representative of accelerated aging and/or alterations in lipid metabolism. Studies in mice indicate that aging or senescence normally decreases $\mathrm{Cx} 43$ expression and function in the heart, ${ }^{65}$ a condition different from the increase observed in our study. Furthermore, studies using SIV-infected monkeys indicate a critical role of CCR5 in gp120-mediated inflammation, recruitment of monocytes/macrophages into the cardiac tissue, and compromise of cardiac muscle and function. ${ }^{66-69}$ Thus, we propose that an additional mechanism of heart disease in the HIV-infected population is altered in Cx43 expression, distribution, and function. Several groups also demonstrated the presence of $\mathrm{Cx} 43$-containing channels on the surface of the mitochondria, ${ }^{12,70,71}$ but the role of this mitochondrial $\mathrm{Cx} 43$ in cardiomyopathy is still under investigation. Our data indicate that both astrocytes and macrophages have compromised and enlarged mitochondria, resulting in significant changes in metabolism and bystander killing mechanisms mediated by connexincontaining channels, GJs, and hemichannels. Future studies will address these intriguing possibilities.

\section{Conclusions}

We consistently detected increased $\mathrm{Cx} 43$ mRNA and protein, altered localization of the protein, calcium accumulation, and deposition of collagen/fibrin in areas with Cx43 overexpression. All of these effects were independent of age, ART (including protease inhibitors), CD4 counts, viral load, and years living with HIV. Our studies in the brain and heart tissue indicate that HIV uses or targets $\mathrm{Cx} 43$ to spread toxicity or inflammation. In the heart, it is not known whether $\mathrm{Cx} 43$ up-regulation by HIV occurs during early infection or is a result of chronic damage by HIV and ART. Our data suggest that $\mathrm{Cx} 43$ channels are a main target of HIV infection in the body, including the brain and the heart. The targeting of Cx43 in all HIV-infected individuals provides a common mechanism of damage and a potential target to reduce or prevent heart disease in the HIV-infected population.

\section{Acknowledgments}

We thank the National NeuroAIDS Tissue Consortium (NNTC) for providing all samples, Dr. Susan Morgello for reading the manuscript, and Dr. Karen Maass (New York University) for providing the $\mathrm{N}$-cadherin antibody.

\section{References}

1. Currier JS, Taylor A, Boyd F, Dezii CM, Kawabata H, Burtcel B, Maa JF, Hodder S: Coronary heart disease in HIV-infected individuals. J Acquir Immune Defic Syndr 2003, 33:506-512

2. Triant VA, Grinspoon SK: Vascular dysfunction and cardiovascular complications. Curr Opin HIV AIDS 2007, 2:299-304

3. Triant VA, Lee H, Hadigan C, Grinspoon SK: Increased acute myocardial infarction rates and cardiovascular risk factors among patients with human immunodeficiency virus disease. J Clin Endocrinol Metab 2007, 92:2506-2512

4. Obel N, Thomsen HF, Kronborg G, Larsen CS, Hildebrandt PR, Sorensen HT, Gerstoft J: Ischemic heart disease in HIV-infected and HIV-uninfected individuals: a population-based cohort study. Clin Infect Dis 2007, 44:1625-1631

5. Choy PC, Siow YL, Mymin D, O K: Lipids and atherosclerosis. Biochem Cell Biol 2004, 82:212-224

6. Hui X, Lam KS, Vanhoutte PM, Xu A: Adiponectin and cardiovascular health: an update. Br J Pharmacol 2012, 165:574-590

7. Vinik AI, Wing RR: The good, the bad, and the ugly in diabetic diets. Endocrinol Metab Clin North Am 1992, 21:237-279

8. Tribulova N, Egan Benova T, Szeiffova Bacova B, Viczenczova C, Barancik M: New aspects of pathogenesis of atrial fibrillation: remodelling of intercalated discs. J Physiol Pharmacol 2015, 66:625-634

9. Singh P, Hemal A, Agarwal S, Kumar D: Cardiac manifestations in HIV infected children. Indian J Pediatr 2015, 82:230-234

10. Pham TV, Torres M: Human immunodeficiency virus infectionrelated heart disease. Emerg Med Clin North Am 2015, 33:613-622

11. Eugenin EA, Basilio D, Saez JC, Orellana JA, Raine CS, Bukauskas F, Bennett MV, Berman JW: The role of gap junction channels during physiologic and pathologic conditions of the human central nervous system. J Neuroimmune Pharmacol 2012, 7:499-518

12. Michela P, Velia V, Aldo P, Ada P: Role of connexin 43 in cardiovascular diseases. Eur J Pharmacol 2015, 768:71-76

13. Antanaviciute I, Ereminiene E, Vysockas V, Rackauskas M, Skipskis V, Rysevaite K, Treinys R, Benetis R, Jurevicius J, Skeberdis VA: Exogenous connexin43-expressing autologous skeletal myoblasts ameliorate mechanical function and electrical activity 
of the rabbit heart after experimental infarction. Int J Exp Pathol 2015, 96:42-53

14. Kurtenbach S, Kurtenbach S, Zoidl G: Gap junction modulation and its implications for heart function. Front Physiol 2014, 5:82

15. Khan Z, Yaiw KC, Wilhelmi V, Lam H, Rahbar A, Stragliotto G, Soderberg-Naucler C: Human cytomegalovirus immediate early proteins promote degradation of connexin 43 and disrupt gap junction communication: implications for a role in gliomagenesis. Carcinogenesis 2014, 35:145-154

16. Fontes MS, van Veen TA, de Bakker JM, van Rijen HV: Functional consequences of abnormal $\mathrm{Cx} 43$ expression in the heart. Biochim Biophys Acta 2012, 1818:2020-2029

17. Gonzalez JP, Ramachandran J, Xie LH, Contreras JE, Fraidenraich D: Selective connexin43 inhibition prevents isoproterenol-induced arrhythmias and lethality in muscular dystrophy mice. Sci Rep 2015, 5: 13490

18. Berman JW, Carvallo L, Buckner CM, Luers A, Prevedel L, Bennett MV, Eugenin EA: HIV-tat alters Connexin43 expression and trafficking in human astrocytes: role in NeuroAIDS. J Neuroinflammation 2016, 13:54

19. Subbian S, Eugenin E, Kaplan G: Detection of Mycobacterium tuberculosis in latently infected lungs by immunohistochemistry and confocal microscopy. J Med Microbiol 2014, 63:1432-1435

20. Rella CE, Ruel N, Eugenin EA: Development of imaging techniques to study the pathogenesis of biosafety level $2 / 3$ infectious agents. Pathog Dis 2014, 72:167-173

21. Marakalala MJ, Raju RM, Sharma K, Zhang YJ, Eugenin EA, Prideaux B, Daudelin IB, Chen PY, Booty MG, Kim JH, Eum SY, Via LE, Behar SM, Barry CE III, Mann M, Dartois V, Rubin EJ: Inflammatory signaling in human tuberculosis granulomas is spatially organized. Nat Med 2016, 22:531-538

22. Thienemann F, Sliwa K, Rockstroh JK: HIV and the heart: the impact of antiretroviral therapy: a global perspective. Eur Heart J 2013, 34: $3538-3546$

23. Reyskens KM, Fisher TL, Schisler JC, O'Connor WG, Rogers AB, Willis MS, Planesse C, Boyer F, Rondeau P, Bourdon E, Essop MF: Cardio-metabolic effects of HIV protease inhibitors (lopinavir/ritonavir). PLoS One 2013, 8:e73347

24. van Kempen MJ, Fromaget C, Gros D, Moorman AF, Lamers WH: Spatial distribution of connexin43, the major cardiac gap junction protein, in the developing and adult rat heart. Circ Res 1991, 68:1638-1651

25. Fromaget C, el Aoumari A, Gros D: Distribution pattern of connexin 43, a gap junctional protein, during the differentiation of mouse heart myocytes. Differentiation 1992, 51:9-20

26. Severs NJ: Gap junction shape and orientation at the cardiac intercalated disk. Circ Res 1989, 65:1458-1462

27. Hoyt RH, Cohen ML, Saffitz JE: Distribution and three-dimensional structure of intercellular junctions in canine myocardium. Circ Res 1989, 64:563-574

28. Eckardt D, Theis M, Degen J, Ott T, van Rijen HV, Kirchhoff S, Kim JS, de Bakker JM, Willecke K: Functional role of connexin43 gap junction channels in adult mouse heart assessed by inducible gene deletion. J Mol Cell Cardiol 2004, 36:101-110

29. Fernandez-Cobo M, Gingalewski C, Drujan D, De Maio A: Downregulation of connexin 43 gene expression in rat heart during inflammation. The role of tumour necrosis factor. Cytokine 1999, 11: 216-224

30. Hesketh GG, Shah MH, Halperin VL, Cooke CA, Akar FG, Yen TE, Kass DA, Machamer CE, Van Eyk JE, Tomaselli GF: Ultrastructure and regulation of lateralized connexin 43 in the failing heart. Circ Res 2010, 106:1153-1163

31. Li C, Meng Q, Yu X, Jing X, Xu P, Luo D: Regulatory effect of connexin 43 on basal $\mathrm{Ca} 2+$ signaling in rat ventricular myocytes. PLoS One 2012, 7:e36165

32. Oyamada M, Tsujii E, Tanaka H, Matsushita T, Takamatsu T: Abnormalities in gap junctions and $\mathrm{Ca} 2+$ dynamics in cardiomyocytes at the border zone of myocardial infarcts. Cell Commun Adhes 2001, 8:335-338
33. Zeng Z, Zhang H, Lin N, Kang M, Zheng Y, Li C, Xu P, Wu Y, Luo D: Role of inositol-1,4,5-trisphosphate receptor in the regulation of calcium transients in neonatal rat ventricular myocytes. J Pharmacol Sci 2014, 126:37-46

34. Delmar M, Makita N: Cardiac connexins, mutations and arrhythmias. Curr Opin Cardiol 2012, 27:236-241

35. Tribulova N, Knezl V, Okruhlicova L, Slezak J: Myocardial gap junctions: targets for novel approaches in the prevention of lifethreatening cardiac arrhythmias. Physiol Res 2008, 57 Suppl 2:S1-S13

36. Gutstein DE, Liu FY, Meyers MB, Choo A, Fishman GI: The organization of adherens junctions and desmosomes at the cardiac intercalated disc is independent of gap junctions. J Cell Sci 2003, 116:875-885

37. Bills CE, Eisenberg H, Pallante SL: Complexes of organic acids with calcium phosphate: the Von Kossa stain as a clue to the composition of bone mineral. Johns Hopkins Med J 1974, 128:194-207

38. Drut R: Calcified mitochondria in epithelial cells of the respiratory tract in upper respiratory thermal injury. Diagn Cytopathol 1998, 19: 288-289

39. Olbrich HG, Herrmann G, Vandeplassche G, Michaelis H, Schneider M, Krause E, Kober G: Calcium overload in human giant cell myocarditis. J Clin Pathol 1990, 43:650-653

40. Boengler K, Stahlhofen S, van de Sand A, Gres P, Ruiz-Meana M, Garcia-Dorado D, Heusch G, Schulz R: Presence of connexin 43 in subsarcolemmal, but not in interfibrillar cardiomyocyte mitochondria. Basic Res Cardiol 2009, 104:141-147

41. Lamont C, Luther PW, Balke CW, Wier WG: Intercellular Ca2+ waves in rat heart muscle. J Physiol 1998, 512(Pt 3):669-676

42. Song D, Liu X, Liu R, Yang L, Zuo J, Liu W: Connexin 43 hemichannel regulates $\mathrm{H} 9 \mathrm{c} 2$ cell proliferation by modulating intracellular ATP and $[\mathrm{Ca} 2+]$. Acta Biochim Biophys Sin (Shanghai) 2010, 42: 472-482

43. Bublitz M, Musgaard M, Poulsen H, Thogersen L, Olesen C, Schiott B, Morth JP, Moller JV, Nissen P: Ion pathways in the sarcoplasmic reticulum Ca2+-ATPase. J Biol Chem 2013, 288: 10759-10765

44. Decrock E, De Bock M, Wang N, Gadicherla AK, Bol M, Delvaeye T, Vandenabeele P, Vinken M, Bultynck G, Krysko DV, Leybaert L: IP3, a small molecule with a powerful message. Biochim Biophys Acta 2013, 1833:1772-1786

45. Dupont G, Combettes L: Fine tuning of cytosolic Ca (2+) oscillations. F1000Res 2016:5

46. Krebs J, Agellon LB, Michalak $\mathrm{M}: \mathrm{Ca}(2+)$ homeostasis and endoplasmic reticulum (ER) stress: an integrated view of calcium signaling. Biochem Biophys Res Commun 2015, 460:114-121

47. Lambert CT, Sandesara PB, Hirsh B, Shaw LJ, Lewis W, Quyyumi AA, Schinazi RF, Post WS, Sperling L: HIV, highly active antiretroviral therapy and the heart: a cellular to epidemiological review. HIV Med 2016, 17:411-424

48. Ntusi N, O'Dwyer E, Dorrell L, Wainwright E, Piechnik S, Clutton G, Hancock G, Ferreira V, Cox P, Badri M, Karamitsos T, Emmanuel S, Clarke K, Neubauer S, Holloway C: HIV-1-related cardiovascular disease is associated with chronic inflammation, frequent pericardial effusions, and probable myocardial edema. Circ Cardiovasc Imaging 2016, 9:e004430

49. Ntusi NB, Taylor D, Naidoo NG, Mendelson M: Progressive human immunodeficiency virus-associated vasculopathy: time to revise antiretroviral therapy guidelines? Cardiovasc J Afr 2011, 22:197-200

50. Grody WW, Cheng L, Lewis W: Infection of the heart by the human immunodeficiency virus. Am J Cardiol 1990, 66:203-206

51. Epstein JE, Eichbaum QG, Lipshultz SE: Cardiovascular manifestations of HIV infection. Compr Ther 1996, 22:485-491

52. Rodriguez ER, Nasim S, Hsia J, Sandin RL, Ferreira A, Hilliard BA, Ross AM, Garrett CT: Cardiac myocytes and dendritic cells harbor human immunodeficiency virus in infected patients with and without cardiac dysfunction: detection by multiplex, nested, polymerase chain reaction in individually microdissected cells from right ventricular endomyocardial biopsy tissue. Am J Cardiol 1991, 68:1511-1520 
53. Lopes de Campos WR, Chirwa N, London G, Rotherham LS, Morris L, Mayosi BM, Khati M: HIV-1 subtype C unproductively infects human cardiomyocytes in vitro and induces apoptosis mitigated by an anti-Gp120 aptamer. PLoS One 2014, 9:e110930

54. Monsuez JJ, Gallet B, Escaut L, Vayre F, Charniot JC, Pulik M, Merad M, Minozzi C, Slama M, Weber S, Vittecoq D: Clinical outcome after coronary events in patients treated with HIV-protease inhibitors. Eur Heart J 2000, 21:2079-2080

55. Monsuez JJ, Gallet B, Escaut L, Vayre F, Pulik M, Charniot JC, Merad M, Slama M, Weber S, Vittecoq D: [Cardiac side effects of anti-HIV agents] French. Arch Mal Coeur Vaiss 2000, 93:835-840

56. Monsuez JJ, Auperin I, Vittecoq D, Heshmati F: Pulmonary hypertension associated with thrombotic thrombocytopaenic purpura in AIDS patients. Eur Heart J 1997, 18:1036-1037

57. Palatinus JA, Rhett JM, Gourdie RG: The connexin 43 carboxyl terminus and cardiac gap junction organization. Biochim Biophys Acta 2012, 1818:1831-1843

58. Eugenin EA: Role of connexin/pannexin containing channels in infectious diseases. FEBS Lett 2014, 588:1389-1395

59. Nath A, Steiner J: Synaptodendritic injury with HIV-Tat protein: what is the therapeutic target? Exp Neurol 2014, 251:112-114

60. Bachani M, Sacktor N, McArthur JC, Nath A, Rumbaugh J: Detection of anti-tat antibodies in CSF of individuals with HIV-associated neurocognitive disorders. J Neurovirol 2013, 19:82-88

61. Malik S, Eugenin EA: Mechanisms of HIV neuropathogenesis: role of cellular communication systems. Curr HIV Res 2016, 14: 400-411

62. Stehberg J, Moraga-Amaro R, Salazar C, Becerra A, Echeverria C, Orellana JA, Bultynck G, Ponsaerts R, Leybaert L, Simon F, Saez JC, Retamal MA: Release of gliotransmitters through astroglial connexin 43 hemichannels is necessary for fear memory consolidation in the basolateral amygdala. FASEB J 2012, 26:3649-3657
63. Orellana JA, Saez JC, Bennett MV, Berman JW, Morgello S, Eugenin EA: HIV increases the release of dickkopf-1 protein from human astrocytes by a Cx43 hemichannel-dependent mechanism. J Neurochem 2014, 128:752-763

64. Calvo M, Martinez E: Update on metabolic issues in HIV patients. Curr Opin HIV AIDS 2014, 9:332-339

65. Bonda TA, Szynaka B, Sokolowska M, Dziemidowicz M, Winnicka MM, Chyczewski L, Kaminski KA: Remodeling of the intercalated disc related to aging in the mouse heart. J Cardiol 2016, 68:261-268

66. Kelly KM, Tocchetti CG, Lyashkov A, Tarwater PM, Bedja D, Graham DR, Beck SE, Metcalf Pate KA, Queen SE, Adams RJ, Paolocci N, Mankowski JL: CCR5 inhibition prevents cardiac dysfunction in the SIV/macaque model of HIV. J Am Heart Assoc 2014, 3:e000874

67. Kelly KM, Tarwater PM, Karper JM, Bedja D, Queen SE, Tunin RS, Adams RJ, Kass DA, Mankowski JL: Diastolic dysfunction is associated with myocardial viral load in simian immunodeficiency virusinfected macaques. AIDS 2012, 26:815-823

68. Walker M, Caldwell RW, Yoon Y, Nguyen TT, Johnson JA: deltaPKC interaction with the $d$ subunit of F1Fo ATP synthase impairs energetics and exacerbates ischemia/reperfusion injury in isolated rat hearts. J Mol Cell Cardiol 2015, 89(Pt B):232-240

69. Walker JA, Beck GA, Campbell JH, Miller AD, Burdo TH, Williams KC: Anti-alpha4 integrin antibody blocks monocyte/macrophage traffic to the heart and decreases cardiac pathology in a SIV infection model of AIDS. J Am Heart Assoc 2015, 4:e001932

70. Gadicherla AK, Wang N, Bulic M, Agullo-Pascual E, Lissoni A, De Smet M, Delmar M, Bultynck G, Krysko DV, Camara A, Schluter KD, Schulz R, Kwok WM, Leybaert L: Mitochondrial Cx43 hemichannels contribute to mitochondrial calcium entry and cell death in the heart. Basic Res Cardiol 2017, 112:27

71. Baines CP: The cardiac mitochondrion: nexus of stress. Annu Rev Physiol 2010, 72:61-80 